\title{
Antibacterial Activity of Copper Nanoparticles and Copper Nanocomposites against Escherichia Coli Bacteria
}

\author{
P.S. Harikumar ${ }^{1}$, Anisha Aravind ${ }^{1}$
}

\author{
${ }^{1}$ Water Quality Division, Centre for Water Resources Development and Management, Kozhikode, India
}

\begin{abstract}
Nanotechnology is an emerging technology which has wide applications in many fields. The major objective of the study is to synthesise copper nanoparticles and its composites and to determine their antibacterial activity. A filter based on the developed material was fabricated. Copper nanoparticles were synthesised by chemical reduction method and were encapsulated in a biopolymer, alginate and fabricated anti bacterial water filter using copper nanoparticle-coated polyurethane foams. The synthesised copper nanoparticle, copper nanoparticle encapsulated in alginate beads and copper nanoparticle coated PU foam were characterized by several techniques including SEM and EDS analysis. Finally antimicrobial efficiency was determined against E.coli. Well diffusion method was used for testing the antibacterial effect of synthesised nanoparticls. The time and dose dependant study of copper alginate beads showed that the effectiveness of particle increase with increasing particle dose and contact time. The results obtained from the effect of bacterial load indicated that there was a decrease in antibacterial activity as the bacterial concentration increased. Flow test was conducted for the antibacterial filter by passing contaminated water through the filter and no bacteria were detected. The antimicrobial activity of metal nanoparticles is due to the large surface area which ensures a broad range of reactions with bio-organics present on the cell surface. Our research suggests that copper-coated polyurethane foams can be used as excellent antibacterial water filter.
\end{abstract}

Keywords: Copper nanoparticles, Copper-alginate beads, Copper nanoparticle coated Polyurethane foam, E.coli, SEM, EDS and Antibacterial activity.

\begin{abstract}
1. Introduction
The adaptation of highly advanced nanotechnology to additional process engineering offers new opportunities for the development of advanced water and waste water technology process. Water can be contaminated by many chemicals and bacteria. Water is the common breeding ground for many pathogens because it contains several bacteria, virus etc. The removal and inactivation of pathogenic microorganisms are the major step in the treatment of water. The presence of E.coli in drinking water would indicate faecal contamination of the water. It is paramount to protect water resources in our country from any source of contamination and to construct water disinfection and delivery systems, as well as sewage treatment facilities that can remove these microorganisms. Advancement in nanoscience and engineering suggest that many of the current problems involving water quality could be resolved by many methods such as nanosorbants,
\end{abstract}

nanocatalysis and nanoparticles enhanced filtration from the development of nanotechnology [1].

The application of metal nanoparticles for water disinfection had been reported by many researchers. Because of their high reactivity due to the large surface to volume ratio [2], nanoparticles are expected to play a crucial role in water purification $[3,4]$, when water becomes an important commodity [5]. The metallic nanoparticles are most promising for disinection as they exhibit high anti bacterial properties due to their large surface area to volume ratio. Copper in the form of nanoparticle has good bactericidal activity. The United States Environmental Protection Agency has approved registration of copper as an antibacterial agent able to reduce specific harmful bacteria linked to potentially deadly microbial infections (European Copper Institute, 2008).

This article is published under the terms of the Creative Commons Attribution License 4.0

Author(s) retain the copyright of this article. Publication rights with Alkhaer Publications.

Published at: http://www.ijsciences.com/pub/issue/2016-02/

DOI: 10.18483/ijSci.957; Online ISSN: 2305-3925; Print ISSN: 2410-4477 
Copper is of natural occurrence in plant and animal tissues where it participates in a number of important roles. To certain limits, the human body has mechanisms available for protection against copper toxicity at the cellular, tissue, and organ levels. It has been reported that $\mathrm{Cu}$ NPs have bactericidal effects comparable to $\mathrm{Ag}$ nanoparticles in single strains of $E$. coli. Typically, antimicrobials kill bacteria by binding to some vital compounds of bacterial metabolism, thereby inhibiting the synthesis of functional biomolecules or impeding normal cellular activities. Nanoparticles attached to the microbial surfaces can decrease both cell mobility and nutrient flow between the cell's exterior and interior compartments. It was reported that [6] copper has the potential to disrupt cell function in multiple ways, since several mechanisms acting simultaneously may reduce the ability of microorganisms to develop resistance against copper. The nonspecific mode of action of nanoparticles against bacteria makes them ideal candidates as antimicrobial agents with less risk of development of bacterial resistance.

The development of polymer based nanocomposites with antimicrobial activity offers interesting possibilities because the polymer matrix can be varied in order to fulfil not only specific technological requirements but also nanostructures with size and shape dependent properties that can be exploited [7]. Among the polymer nanocomposites investigated so far, those incorporating $\mathrm{Ag}$ and $\mathrm{Cu}$ nanoparticles have been regarded as particularly useful for applications in various fields, including biomedical equipment and devices, water treatment, and food processing. The great interest for $\mathrm{Cu}$ based composites can be easily perceived by the number of polymer matrices investigated in their preparation, both of synthetic and natural origin. Alginate is a biopolymer which exhibit bactericidal property. We had used copper nanoparticles coated with alginate and enhance the antibacterial property.

A study on water bactericidal properties of Nanosilver-polyurethane composites revealed that nanosilver particles adsorbed onto polyurethane foam exhibited a marked activity against certain species of water-borne bacteria [8]. Polyurethane foams have been particularly singled out for this purpose owing to their possession of the carbomate group. This support was chosen because the _N(H)COO_ (carbamate) group is expected to bind with the surface of the nanoparticles. It is also one of the most cost-effective, food-grade polymers available, and it has a considerable application possibility in rural communities. E. coli was chosen in this study as indicators of faecal contamination. Several investigations have been done on supports such as polypropylene and textile fabrics [9] for exploring bactericidal effect. The introduction of copper nanoparticles onto porous material such as polyurethane, might lead to further enhancement of their bactericidal activity. Such modifications have been very useful in the fabrication of water filter. We are reporting the antibacterial activity of copper nanoparticles and its composites in this paper.

\section{Methodology}

\subsection{Materials}

All chemicals used were of analytical grade purchased from MERCK (India).

\subsection{Synthesis of Copper nanoparticles}

The nanoparticles were synthesised by chemical reduction method [10]. In the synthesis of copper nanoparticles, requisite amount of $\mathrm{CuSO}_{4}$ and EDTA were dissolved in deionised water. $\mathrm{KBH}_{4}$ was added to the above solution drop wise as reducing agent, and then the solution was heated. After stirring at different temperatures for a certain time, the aqueous solution was filtered. The product was washed thrice with ethanol and acetone separately, and finally dried in an oven.

\subsection{Determination of antibacterial efficiency}

The antimicrobial activity of the synthesised copper nanoparticles was assessed by using pure culture of Escherichia coli (E. coli). Copper nanoparticles were tested in vitro for their antimicrobial activities against strains by the agar diffusion technique. The pathogenic bacteria was maintained on nutrient agar in Petri dishes with an inner diameter $9 \mathrm{~cm}$ to provide thin agar plates after solidification of thickness 3.4$3.5 \mathrm{~mm}$. After solidification, hollows of 10 millimetre diameter wells were cut from the agar using a sterile cork-borer and $50 \mu \mathrm{l}$ of nanoparticles suspension was dispensed onto each well on the plate. The Petri dishes were incubated at $5-8^{\circ} \mathrm{C}$ for $2-3 \mathrm{~h}$ to permit good diffusion and then incubated for $24 \mathrm{~h}$ at $37^{\circ} \mathrm{C}$ in case of bacteria. After incubation the diameter of inhibition zone (mm) was measured [11].

\section{4. Synthesis of copper nanoparticles encapsulated in alginate beads}

Copper nanoparticles were immobilized by entrapment in calcium alginate beads. Four percentage solution of sodium alginate was prepared by dissolving sodium alginate in deionised water kept in a water bath at $65^{\circ} \mathrm{C}-75^{\circ} \mathrm{C}$. The solution was stirred with a sterile glass rod. Eight percentage of $\mathrm{CaCl}_{2}$ was prepared by dissolving calcium chloride in deionised water. Two gram $\mathrm{Cu}$ nanoparticle was added to it to synthesise beads containing $\mathrm{Cu}$. By using a micropipette, the sodium alginate solution was added drop wise to $\mathrm{Cu}$-calcium chloride solution which was vigorously stirred using magnetic stirrer. Each drop changed in to a bead of calcium alginate on which $\mathrm{Cu}$ was entrapped. The beads were maintained in $\mathrm{CaCl}_{2}$ solution at $4{ }^{\circ} \mathrm{C}$ overnight. The 
beads were poured into a $500 \mathrm{ml}$ conical flask and rinsed with $250 \mathrm{ml}$ deionised water. The excess water in the beads was removed by blotting with filter paper [12]. Then, the beads were washed with distilled water and dried.

\subsection{Batch study for determining the antibacterial activity of synthesised beads}

A batch study was conducted to investigate the effect of quantity of nanoparticle, contact time and effect of bacterial load on bacterial reduction. The effect of the parameters on the adsorbent dosage $(2,4,6,8$ and 10 g), contact time $(2,4,6$ and $10 \mathrm{hr})$ and bacterial load (460, 500,540,580 and $620 \mathrm{CFU})$ was studied. To the copper alginate beads taken in different conical flasks, $30 \mathrm{ml}$ of sample was added. Then the samples were kept in orbital shaker for different time intervals. Then it was filtered and spread plating was done and incubated. A control was also kept.

\subsection{Column study}

Column study was also conducted using copper alginate beads. Continuous flow adsorption experiments were conducted in a cylindrical glass column $(2 \mathrm{~cm}$ internal diameter and $30 \mathrm{~cm}$ height $)$. At the bottom of the column, a glass wool was attached. Known quantities of copper alginate beads were placed into the column, to yield bed height of $20 \mathrm{~cm}$. At the top of the column, the samples were pumped through the packed column at a flow rate of 8 $\mathrm{ml} / \mathrm{min}$, using a peristaltic pump. Samples were collected at the column outlet at different time intervals and were subjected to microbiological tests.

\subsection{Microbiological Tests}

Antibacterial action of $\mathrm{Cu}$ nanoparticle was studied using Colony Forming Unit (CFU). In CFU detection method, samples treated with copper nanoparticles were spread on nutrient agar plates and after incubation at $37{ }^{\circ} \mathrm{C}$ for 24 hour and the number of $\mathrm{CFU} / \mathrm{ml}$ was counted.

\subsection{Determination of Percentage Reduction of Bacterial Count \\ Percentage reduction of bacterial count = Initial CFU - Final CFU/Initial CFU $\times 100$}

2.9. Preparation of Copper nanoparticlePolyurethane Foam (Cu - PU) Composite

Copper coated PU foams were prepared by modifying the procedure [13]. Sheets of polyurethane foam were soaked in carbon tetrachloride solution and then evaporated. These evaporated polyurethane foams were again soaked in copper nanoparticle solution overnight. The sheets were washed repeatedly with de-ionised water to remove any loosely adsorbed ions and subsequently allowed to dry under ordinary air currents. The resulting $\mathrm{Cu}-\mathrm{PU}$ composite foams were subjected to characterisation.

\subsection{Test-tube Test}

Tube test was conducted using $10 \mathrm{ml}$ of aliquots of $E$. coli which was suspended in deionised water and drawn into previously sterilised test-tubes. $1 \mathrm{~cm}^{3}$ cubes of the stiff and dry nanocopper polyurethane foam composite were cut with the help of sterile scissors and immersed, one piece in each of the test suspensions. After $10 \mathrm{~min}$, the foams were drawn out from the tubes and was transferred into another empty tube and pressed to squeeze out the supposedly treated elute water. The pour plate method was carried out with this elute on 1-, 100- and 10,000-fold dilutions. Plating using $0.05 \mathrm{~mL}$ of solution was also performed for the initial CFU count and on the elute obtained after pressing uncoated polyurethane. The plates were in each case to incubated for $12 \mathrm{~h}$ at $37^{\circ} \mathrm{C}$ [14].

\subsection{Fabrication of water filter}

Experimental arrangement consists of a round fibre glass jar which had an opening at the top side. Water filter was inserted to the jar through the opening. It consists of six layers in which small pebbles, charcoal, fine sand, large pebbles, coarse sand and polyurethane coated Copper nanoparticles were packed from bottom to top respectively. Contaminated water sample was added through the opening and the treated water was collected at the outlet.

\subsection{Flow test}

Water sample was added to the filter. Flow rate was adjusted to $50 \mathrm{ml} / \mathrm{min}$. Total Coliforms and E. coli were determined by Most Probable Number (MPN).

\subsection{Characterization of nanoparticles}

\subsection{3. a. Scanning Electron Microscopy}

Size and morphology of the nanoparticles was examined by SEM. SEM images were observed with a magnification $10.00 \mu \mathrm{m}$ with an accelerating voltage of $10 \mathrm{kV}$.

\subsection{3. b. Energy Dispersive Spectroscopy}

EDS analyser was used for the determination of elemental composition and purity of the samples by atom percentage of metal. Elemental analysis of nanoparticles was carried out using EDS instrument in a resolution of $60 \AA$, with a magnification of about $5 \mathrm{k}$. Samples were prepared on a carbon coated copper grids and kept under vacuum desiccation for $3 \mathrm{~h}$ before loading them onto a specimen. 


\section{Result and Discussions}

\subsection{Characterisation of nanoparticles}

\section{1. a. Scanning electron microscopy}

Scanning electron micrograph of the synthesized nanoparticles is presented in Figure 1. The micrograph shows that the appearance of the particles is spherical in shape. Synthesized particles do not appear as discrete one but form much larger particles. The size of $\mathrm{Cu}$ nanoparticles range from $60-300 \mathrm{~nm}$. The observations of such larger nanoparticles are composed of Vanderwaals clusters of smaller entities.
SEM images of $\mathrm{Cu}$ coated PU foams, proved clearly the presence of $\mathrm{Cu}$ nanoparticles in polyurethane foam sheets (Fig.2 (a, b, c). The polyurethane maintained its morphology upon coating with copper nanoparticles. The particles are uniformly adsorbed onto the polyurethane surface.

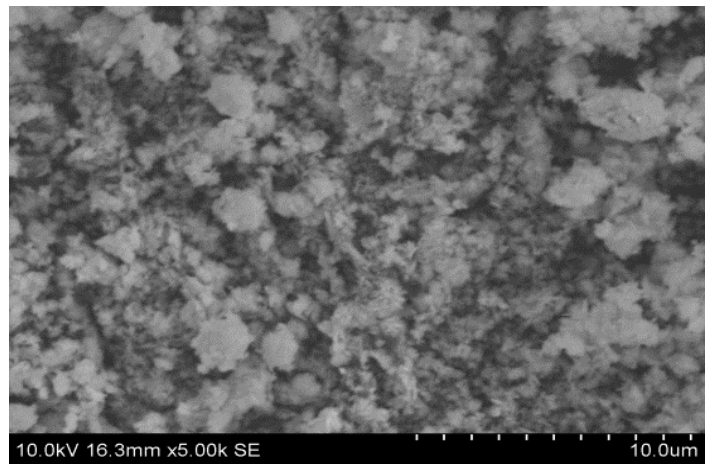

Fig( 1): Scanning electron micrograph of copper nanoparticles
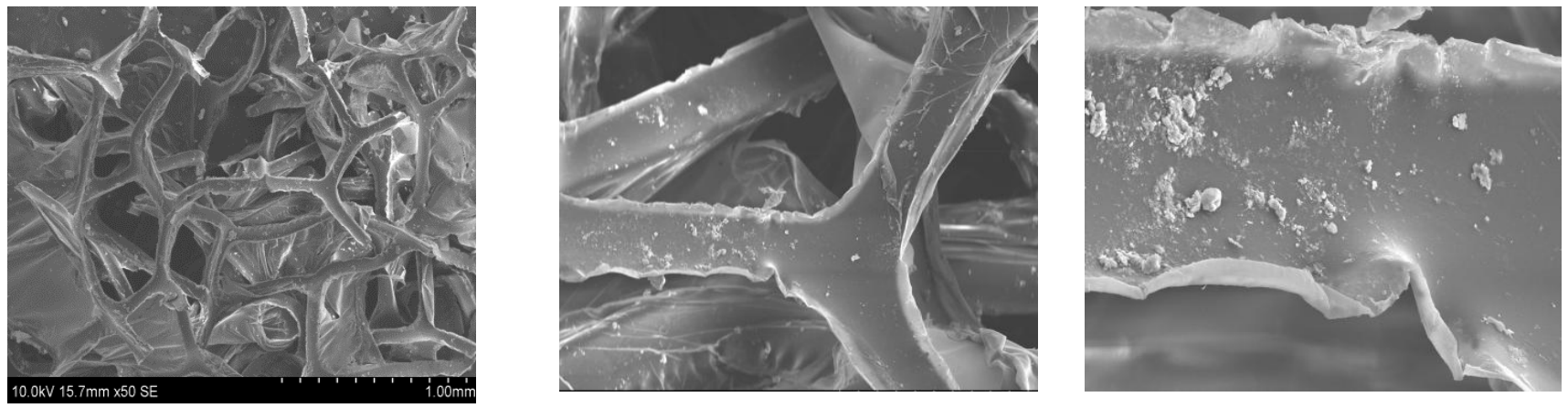

Fig 2 (a, b, c): Scanning electron micrographs of copper nanoparticles coated in PU foam at different magnifications

\section{1. b. Energy dispersive spectroscopy}

EDS micrograph explains the surface atomic distribution and chemical composition of nanoparticles. Quantitative measuring results obtained from, EDS analysis reflect that $100 \%$ atom particles were of copper nanoparticle which confirms the purity of copper metal. EDS spectrum of $\mathrm{Cu}$ coated PU foam also indicates the presence of $\mathrm{Cu}$ nanoparticles in polyurethane foam.

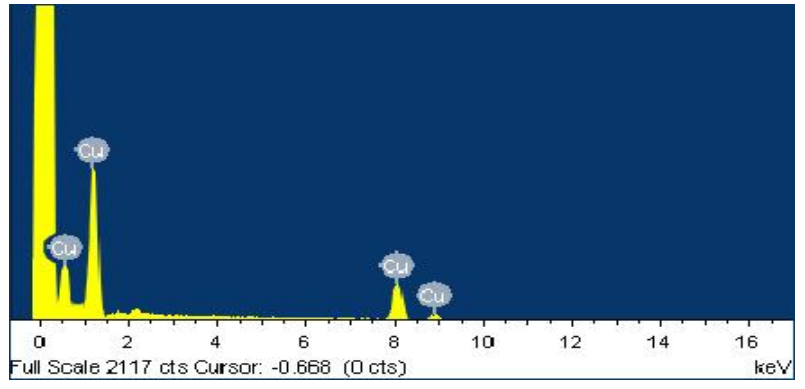

Fig (3): Energy dispersive spectrum of Copper NP 


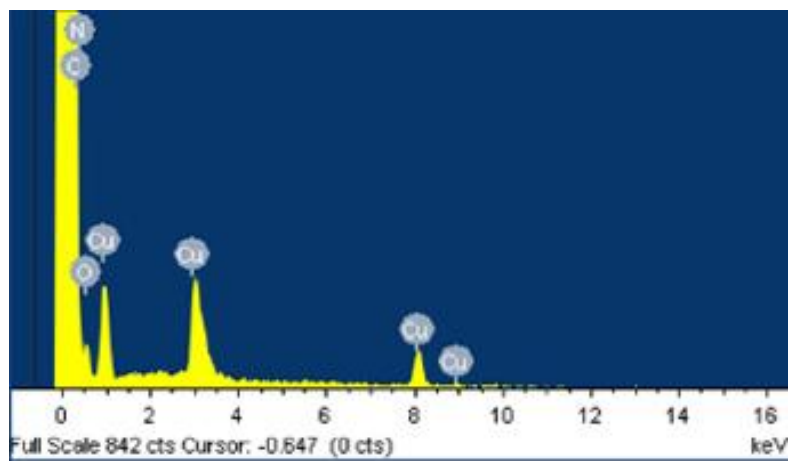

Fig (4): Energy dispersive spectrum of Copper NP

\subsection{Antibacterial Effect}

Based on the observations, it can be perceived that very high rate of activity against the bacterial strains was reported. Copper nanoparticles exhibit high antibacterial activity. The zone values obtained was $12 \mathrm{~mm}$. MPN value also indicated absence of bacteria. The presence of an inhibition zone clearly indicates the mechanism of the biocidal action of nanoparticles involves disrupting the membrane. Extend of inhibition depends on the concentration of nanoparticles as well as on the initial bacterial concentration.

\subsection{Batch adsorption study}

In the batch adsorption study, different conditions were applied to check the efficiency of the treatment.

\subsubsection{Effect of the Quantity of Copper Alginate Bead}

Copper alginate bead exhibited antibacterial activity. Dose dependent study of copper nanoparticles showed that the effectiveness of particles increased with increasing particle dose. The mortality rate increases continuously with the increase of nanomaterial concentration and their antibacterial activities are dose dependant [15].

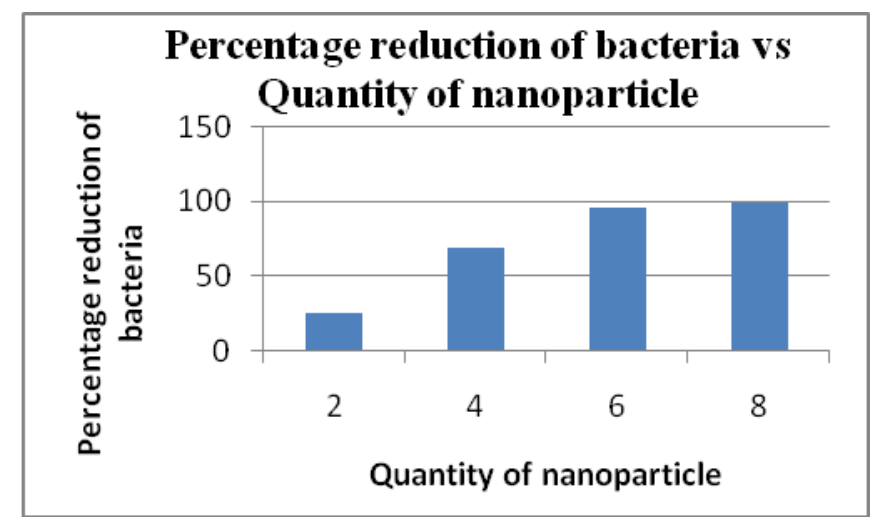

Fig (5): Graph representing the percentage reduction of bacteria vs quantity of nanoparticle

\subsubsection{Effect of Contact time}

Antibacterial efficiency increased with increase in contact time. As contact time increased, there was greater chance for bacteria - nanoparticle interaction. 


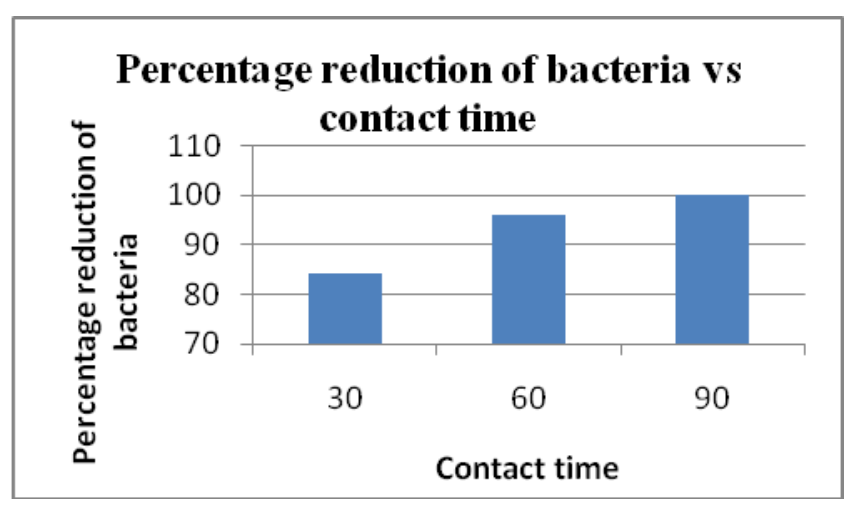

Fig (6): Graph representing the percentage reduction of bacteria vs contact time

\subsubsection{Effect of Bacterial Load}

From the obtained result, it was found that as the bacterial concentration increased, there was slight decrease in the percentage reduction of bacteria.

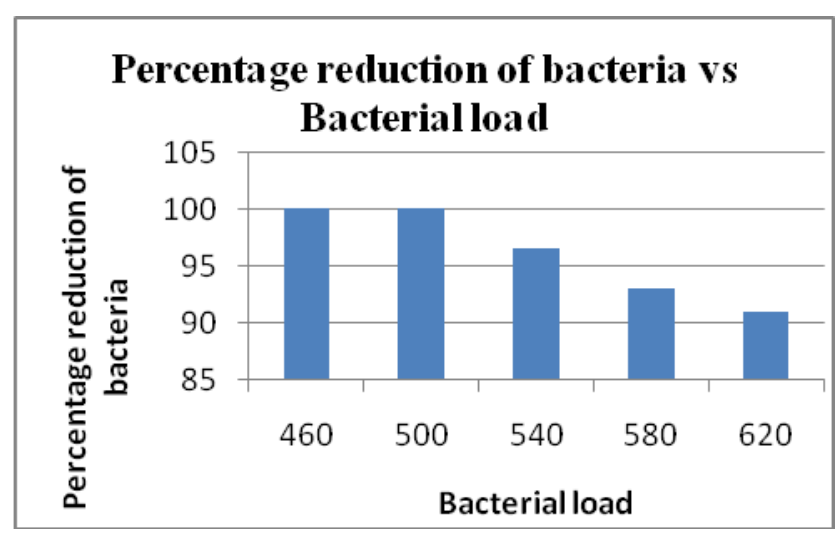

Fig (7): Graph representing the percentage reduction of bacteria vs bacterial load

\subsection{Column Study}

Column study revealed that as the retention time increased bacteria were removed completely. In this study $100 \%$ antibacterial efficiency was attained after $6 \mathrm{hr}$. Copper alginate bead exhibited bactericidal property.

\subsection{Microbiological test on $\mathrm{Cu}$-coated} polyurethane

\subsubsection{Test tube test}

The results of microbiological test in tube test condition indicated that the E.coli was killed after 1 hr with the antibacterial efficiency of above $91 \%$ being observed, and were killed completely after 6 hrs for all $\mathrm{Cu}$-coated polyurethane sheets. Contrary to $\mathrm{Cu}$-coated polyurethane sheets, it was found that colony density of uncoated polyurethane sample (N0) increase significantly when the soaking time was increased. 
Table 1: Colony density and Gram-negative (E.coli) antibacterial efficiency of Cu-coated Polyurethanefoam 3.5.2. Flow Test

\begin{tabular}{|c|c|c|c|c|c|c|}
\hline \multirow[t]{2}{*}{ Samples } & \multicolumn{3}{|c|}{$\mathrm{Ni}(\mathrm{CFU} / \mathrm{ml})$} & \multicolumn{3}{|c|}{$\eta(\%)$} \\
\hline & 1hr & $6 \mathrm{hr}$ & $24 \mathrm{hr}$ & $1 \mathrm{hr}$ & $6 \mathrm{hr}$ & $24 \mathrm{hr}$ \\
\hline $\begin{array}{l}\text { N0 }\left(2.20 \times 10^{3}\right) \\
\text { N1 }\left(1.8 \times 10^{4}\right) \\
\text { N2 }\left(3.5 \times 10^{6}\right) \\
\text { N3 }\left(4.62 \times 10^{6}\right)\end{array}$ & $\begin{array}{l}2.35 \times 10^{4} \\
1.50 \times 10^{5} \\
2.75 \times 10^{5} \\
3.10 \times 10^{6}\end{array}$ & $\begin{array}{l}1.65 \times 10^{5} \\
0 \\
0 \\
0\end{array}$ & $\begin{array}{l}1.20 \times 10^{7} \\
0 \\
0 \\
0\end{array}$ & $\begin{array}{l}0 \\
91.7 \\
92 \\
93\end{array}$ & $\begin{array}{l}0 \\
100 \\
100 \\
100\end{array}$ & $\begin{array}{l}0 \\
100 \\
100 \\
100\end{array}$ \\
\hline
\end{tabular}

The results of the microbiological test on $\mathrm{Cu}$-coated polyurethane foam in flow test condition confirmed the antibacterial property of these materials. Input water samples, sample 1 had total coliforms of 60 MPN/100 ml, E.coli density of 40 MPN/100 ml, sample 2 had coliforms density of 85 MPN/100 ml, E.coli density of $60 \mathrm{MPN} / 100 \mathrm{ml}$ and coliforms density of 130, E.coli density of 90 . After testing the three samples, it was found that no bacteria were detected.

Table 2: The Coliforms and E. coli density results of water treated with $\mathrm{Cu}$-coated and Uncoated polyurethane water filter

\begin{tabular}{|l|l|l|l|l|}
\hline \multirow{2}{*}{ Samples } & \multicolumn{2}{|l|}{ Coliforms Density (MPN/100ml) } & E.coli Density (MPN/100ml) \\
\cline { 2 - 5 } & $\begin{array}{l}\text { Uncoated } \\
\text { PU }\end{array}$ & Cu-coated PU & Uncoated PU & Cu-coated PU \\
\hline N1 & 60 & 0 & 40 & 0 \\
N2 & 85 & 0 & 60 & 0 \\
N3 & 130 & 0 & 90 & 0 \\
\hline
\end{tabular}

3.6. The antibacterial mechanism of copper nanoparticle against bacteria

The exact mechanisms of NP toxicity against various bacteria are not understood completely. NPs are able to attach to the membrane of bacteria by electrostatic interaction and disrupt the integrity of the bacterial membrane [16]. The mechanisms of NP toxicity depend on composition, surface modification, intrinsic properties, and the bacterial species. There Antibacterial activities of nanoparticles depend on two main factors: (i) physicochemical properties of nanoparticles and (ii) type of bacteria.

The toxicity of copper nanoparticles depends on the combination of several factors such as aeration, concentration of nanoparticles and concentration of bacteria (E. coli). The high aeration decreases the agglomeration and increase the toxicity. In fact, the lower agglomeration provides more available surface area for interaction with bacterial membranes and for solubilisation of copper ions, which leads to more toxicity. Metallic and ionic forms of copper produce hydroxyl radicals that damage essential proteins and DNA [17]. Copper dissolves on surface of the bacteria and penetrate to the bacteria cells thereby breaking cell membrane. Due to the stresses caused by copper atoms and other phenomena leading to loss of membrane potential and cytoplasmic contents, copper ions stimulate development of reactive oxygen forms which causes further damages of cells and finally genome and plasmid DNA is subject to degradation [18].

\section{4. Conclusion}

The antibacterial test conducted using the synthesised copper nanoparticles proved that the nanoparticles have high anti bacterial efficiency. Copper nanoparticles exhibited inhibitory effect on the growth of $E$. coli strain. Hence copper nanoparticles can be considered as potential antibacterial agent.

The batch experiments conducted using copper 
nanoparticle encapsulated alginate beads, indicated that optimum dosage of nanoparticle and contact time for reduction of bacterial growth was found to be 8 gm and 60 minutes respectively with the maximum efficiency of $100 \%$. The percentage reduction of bacteria increased with quantity of nanoparticle and contact time. The column study also suggested that copper alginate beads exhibit antibacterial efficiency and $100 \%$ bacterial removal was observed at a contact time of $6 \mathrm{hr}$. Hence we can conclude that, the efficiency of copper alginate beads to reduce bacterial concentration was remarkably high.

The Cu-coated polyurethane foams were fabricated successfully. The results of the microbiological test on $\mathrm{Cu}$-coated polyurethane in tube test condition showed that these materials exhibited highly efficient Gram-negative antibacterial property. The results of the microbiological test on $\mathrm{Cu}$-coated polyurethane in flow test condition confirmed the antibacterial property of these materials. This study suggests that copper-coated Polyurethane foams can be used as excellent antibacterial water filters and could offer several applications in other sectors with simple treatment system.

\section{References}

1. Diallo, M.S., Savage N, Diallo M S (2005). J. Nanomaterials and water purification opportunities and challenges. Nanopart. Res. 7:331 - 342.

2. Ichinose, N., Ozaki, Y. and Kashu, S. (1992). Superfine particle technology. Ch. 5, Springer Verlag. New York.

3. Stoimenov P, Klinger R, Marchin GL, Klabunde KJ (2002) Metal oxide nanoparticles as bactericidal agents. Langmuir 18 (17), 6679-6686.

4. Knight V, Sanglier J-J, Di Tullio D, Braccili S, Bonner P, Waters J, Hughes D, Zhang L (2003) Diversifying microbial natural products for drug discovery. Appl Microbiol Biotechnol 62:446-458.

5. Barraque B. 2003. Past and future sustainability of water policies in Europe. Nat Resources Forum 27:200-211.

6. Raffi M, Mehrwan S, Bhatti TM, Akhter JI, Hameed A, Yawar W, Hasan MM. Investig ations into the antibacterial behavior of copper nanoparticles against Escherichia coli. Annals of Microbiology. 2010; 60:75-80.

7. Pinto R.J.B., Neves M.C., Pascoal Neto C., and Trindade T. (2012) "Composites of cellulose and metal nanoparticles," in Nanocomposites-New Trends and Developments, Ebrahimi F., Ed., pp. 73- 96, InTech, Rijeka, Croatia.

8. Mulongo, G., Mbabazi, J., Hak Chol, S., 2011. Synthesis and Characterisation of Silver Nanoparticles using High Electrical Charge Density and High Viscosity Organic Polymer Res: J.Chem.Sci. 1(4), 18 - 21.

9. Yeo S.Y., Lee H.J., and Jeong S.H, Preparation of nanocomposite fibers for permanent antibacterial effect. J. Mater. Sci. 38, 2143 (2003).

10. Jin, J., Zhang, Z., Ma, H., Lu, X., Chen, J., Zhang, Q., Zhang, H. and Ni, Y., Surface modification of spherical magnesium oxide with ethylene glycol. Materials Letters, 63, 1514-1516 (2009).

11. Selvarani T., Karthieya Prabhu B., Thenmozhi K. (2013). Effect of aqueous extract from the sea weed, Sargassum illicifolium, on three types of non pathogenic terrestrial bacteria. Int J.of Med. Arom. Plants, ISSN 2249 - 4340. Vol No 3, No 2, pp 169 - 177.

12. Margaret E Lyn and DanYang Ying: Drying model for calcium alginate beads. Ind. Eng. Chem. 2010, 49: 19861990.

13. Phong N.T.P., Thanh N.V.K, Phuong P.H., Fabrication of antibacterial water filter by coating silver nanoparticles on flexible polyurethane foams. J Phys: Conf Ser 2005; 187:012079.

14. Mulongo, G., Mbabazi, J., Hak Chol, S., 2011. Synthesis and Characterisation of Silver Nanoparticles using High Electrical Charge Density and High Viscosity Organic Polymer Res: J.Chem.Sci. 1(4), 18 - 21.

15. Shaobin, L., H. Ming, H. Tingying, W. Ran, J. Rongrong, W. Jun, W. Liang, K. Jing and Yuan, C.2012. Lateral Dimension-Dependent Antibacterial Activity of Graphene Oxide Sheets. ACS Nano. 28: 1236412372.

16. Thill A, Zeyons O, Spalla O, Chauvat F, Rose J, Auffan M, et al. Cytotoxicity of $\mathrm{CeO} 2$ nanoparticles for Escherichia coli. Physico-chemical insight of the cytotoxicity mechanism Environ Sci Technol. 2006; 40(19):6151-6.

17. Wang J, Liu H, Kurt'an T, M'andi A, S'andor A, Jia L, Zhang H, Guo Y (2011) Protolimonoids and norlimonoids from the stem bark of Toona ciliata var. pubescens. Org Biomol Chem 9(22):7685-7696.

18. Dupont, C.L., Grass, G., Rensing, C., 2011. Copper toxicity and the origin of bacterial resistance-new insights and applications. Metallomics 2011 Oct 10. 